\title{
P02-218
}

\section{THE SOCIAL AND PSYCHOLOGICAL CORRELATES OF HAPPINESS IN SEVENTEEN EUROPEAN COUNTRIES: ANALYSIS} OF DATA FROM THE EUROPEAN SOCIAL SURVEY

\author{
A. Doherty ${ }^{1}$, B. Kelly ${ }^{1,2}$ \\ ${ }^{1}$ Department of Adult Psychiatry, Mater Misericordiae University Hospital, ${ }^{2}$ Department of Psychiatry, University College Dublin, \\ Dublin, Ireland
}

Background: Happiness has been associated with a number of individual and societal factors, but much of the individual-toindividual variation in happiness remains unexplained. The purpose of this paper is to examine a broad range of social and psychological correlates of self-rated happiness in Europe.

Methods: We used data from the European Social Survey to determine levels of happiness in individuals $(n=30,816)$ from seventeen European countries and to identify associations between happiness and age, gender, family relationships, satisfaction with income, employment status, community trust, satisfaction with health, satisfaction with democracy, religious belief and country of residence.

Results: Self-rated happiness varies significantly between European countries, with individuals in Denmark reporting the highest levels of happiness and individuals in Bulgaria reporting the lowest levels. On multi-variable analysis, happiness is positively correlated with younger age, satisfaction with household income, being employed, high community trust and religious belief. Overall, these factors account for $22.5 \%$ of the individual-to-individual variation in happiness in Europe.

Conclusion: For the individual, this study highlights the strength of association between happiness and the individual's attitudes towards various aspects of their personal, household and societal circumstances. For social policy-makers, this study confirms the potential usefulness of civic measures to increase community trust and social capital. Further studies of the inter-relationships between individual and community-level variables would assist in further explaining the variance in happiness between individuals and countries. 